and female patients may be different". The experience of the prison service (Moulden, 2000) makes a bold case for small, locally determined units that could clearly meet the required objectives, with the added benefit of minimum disruption to local services and social networks.

DEPARTMENT OF HEALTH (1999) National Service Framework for Mental Health, Modern Standards and Service Models. London: Stationery Office.

HOME OFFICE (1997) Women in Prisons: A Thematic Review by HM Chief Inspector of Prisons. London: The Home Office.

MOULDEN, M. (2000) Women prisoners with ment health problems. Prison Service Journal, 126, 11-12.

Andrew Forrester Lecturer in Forensic Psychiatry, Camlet Lodge RSU, Chase Farm Hospital, The Ridgeway, Enfield EN2 8JL

\section{Mental Health Act reform: treatment of dangerous and severe personality disorder}

Sir: Chiswick (Psychiatric Bulletin, August 2001, 25, 282-283) has captured the essence of the proposed Mental Health Act reforms with regard to dangerous and severe personality disorder (DSPD).

The existing Mental Health Act always gave clinicians the power to detain patients with psychopathic disorder in a hospital for treatment if the patient was thought to present risks to others. Treatment of patients with psychopathic disorder is stressful because of the difficulties in treating them, the resources they take up, the strong countertransference reactions these patients evoke and the staff burnout that they cause. Therefore, understandably, clinicians resort to a narrow interpretation of the 'treatability test'

In the proposed reforms, the emphasis is on the fact that this group of patients needs treatment and that the interpretation of the treatability test needs to be a broad one.

The main arguments put forward by clinicians against the proposals are that (a) patients who are not treatable should not be detained and (b) it is unethical to detain patients for public protection alone.

Taking the first argument about treatability of psychopathy, there is a lot of evidence in the literature that psychopathy can be a difficult condition to treat, but not entirely untreatable.

As to whether it is unethical to detain patients when they pose a risk to others it can be argued that because of the high probability of their offending, patients with DSPD run a high risk of being imprisoned and being the victims of retaliation by others and therefore detention in hospital prevents offending behaviour and protects them from the consequences thereof.

If we as clinicians refuse to treat people who are clearly unwell and distressed, we would be failing in our duty of care and pushing these vulnerable patients into the criminal justice system.

Since it seems inevitable that the proposals will become law, we should be fighting for more resources to be able to deliver the services this group of patients need.

Prabhat Mahapatra, Consultant Psychiatrist, Care Principles, Dover Road, Barham, Canterbury CT4 6PW

\section{Impoverished services for poor people - perceived racism in psychiatric services}

Sir: Sashidharan's article on institutional racism in British psychiatry (Psychiatric Bulletin, July 2001, 25, 244-247) failed to mention a major issue that in my experience is crucial to this debate. Black and other ethnic minorities are more likely than the general population to be poor and socially disadvantaged and live in areas that generate high psychiatric morbidity, but where mental health services are likely to be similarly impoverished and deprived. This alone may account for much that is objectionable and countertherapeutic in the experience of Black psychiatric patients.

We recently demonstrated the importance of inequality in a randomised controlled trial of community care for recently discharged patients in Brent and Westminster (Tyrer et al, 1998). This study showed that although community care reduced admissions to hospital compared to hospital-based care, this only made a worthwhile impact where there were adequate numbers of hospital beds.

As Sashidharan points out, it is undeniable that many Black people experience psychiatric services as noxious and alienating. However, he is selective in focusing almost exclusively on the providers of psychiatric services in searching for the causes and remedies.

TYRER, P., EVANS, K., GANDHI, N., et al (1998) Randomised controlled trial of two models of care for discharged psychiatric patients. BMJ, 316, 106-109.

P. Harrison-Read Consultant Psychiatrist Department of Psychiatry, Royal Free Hospital, Pond Street, London NW3 206

\section{Driving and mental illness}

Sir: Wise and Watson's survey of psychiatrists' knowledge and attitude towards driving and mental illness (Psychiatric Bulletin, September 2001, 25, 345-349) importantly describes the prevalent lack of knowledge and/or willingness to apply the existing Driver and Vehicle Licensing Agency (DVLA) regulations.

They omit to mention patients with dementia who are probably the largest and potentially the most at-risk group of drivers with mental illness.

Driving while suffering from relatively mild dementia (of Alzheimer's or vascular aetiology) can pose a significant risk to other road users and occasionally result in incidents leading to newspaper headlines such as 'pensioner drives wrong way along motorway'.

The majority of patients with dementia are cared for by their general practitioners and it is primarily their responsibility to be aware of DVLA regulations and to apply them rigorously. This will almost inevitably cause friction in the doctor-patient relationship as many elderly car owners view their right to drive as their only means of continuing to lead an independent life.

Suggestions to patients that they should cease driving are frequently countered by responses such as 'I only go to the shops twice a week on the same route' or 'I've driven for 50 years without problems'.

Allowing a patient to drive while being aware that he/she has a progressive dementing illness could expose the doctor to serious medico-legal consequences.

As the prevalence of dementia rises rapidly in the 8th decade, I suggest there should be more frequent testing of driving ability, possibly including brief tasks of cognitive function for all drivers over the age of 70 .

Stephen Edwards, Medical Director/Consultant sychiatrist, Edward Street Hospital, West Bromwich, West Midlands B70 8NL

\section{Home treatment service}

Sir: I read with interest the study by Harrison et al (Psychiatric Bulletin, August 2001, 25, 310-313) about which patients are suitable for a home treatment service. The authors are right to comment that little has been written about the type of patient suitable for this approach. However, this question may be premature, in that there is little agreement about what 'the approach' actually involves. Their own particular model is described as a hybrid between day hospital and home treatment, which is rather an unusual configuration for home treatment services.

The authors write as if there is a strong evidence-based rationale for the development of acute home treatment services. Despite their incorporation in the National Service Framework for Mental Health, there is not. Their referral to "key components of the model" is highly 